\title{
Two-step endoscopic ultrasound-guided rendezvous technique combined with antegrade electrohydraulic lithotripsy for a huge pancreatic duct stone
}

The endoscopic ultrasound-guided rendezvous technique (EUS-RV) is a useful procedure for difficult cannulation of not only the bile duct, but also the pancreatic duct [1-4]. In addition, if guidewire passage from the papilla across the obstructed site is challenging, antegrade guidewire insertion under EUS guidance is one of several possible methods. Herein, we describe a two-step EUS-RV technique combined with antegrade electrohydraulic lithotripsy (EHL) for a huge pancreatic duct stone.

A 48-year-old man was admitted to our hospital with obstructive jaundice and acute pancreatitis due to chronic pancreatitis that was complicated by a huge pancreatic duct stone. Endoscopic retrograde cholangiopancreatography (ERCP) was therefore attempted. First, biliary drainage using a fully covered metal stent was successfully performed. Pancreatic duct drainage was then attempted; however, although pancreatic duct cannulation could be performed, passage of the guidewire failed. Therefore, EUS-guided pancreatic duct drainage was performed using a 6 -mm covered metal stent.

After 1 week, the covered metal stent was removed and, to obtain partial stone fragmentation, antegrade EHL was attempted using a digital single-operator cholangiopancreatoscope (SPY-DS; Boston Scientific) ( Fig. 1 and Fig.2). After stone fragmentation had been partially obtained, guidewire passage beyond the huge pancreatic duct stone was again attempted, with the guidewire this time being successfully deployed

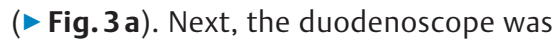
removed, leaving the guidewire in position, before the scope was advanced again to the region of the papilla. The guidewire was grasped using biopsy forceps ( $\triangleright$ Fig. $\mathbf{3 b}$ ) and pulled into the scope channel. An ERCP catheter was then inserted, with successful passage

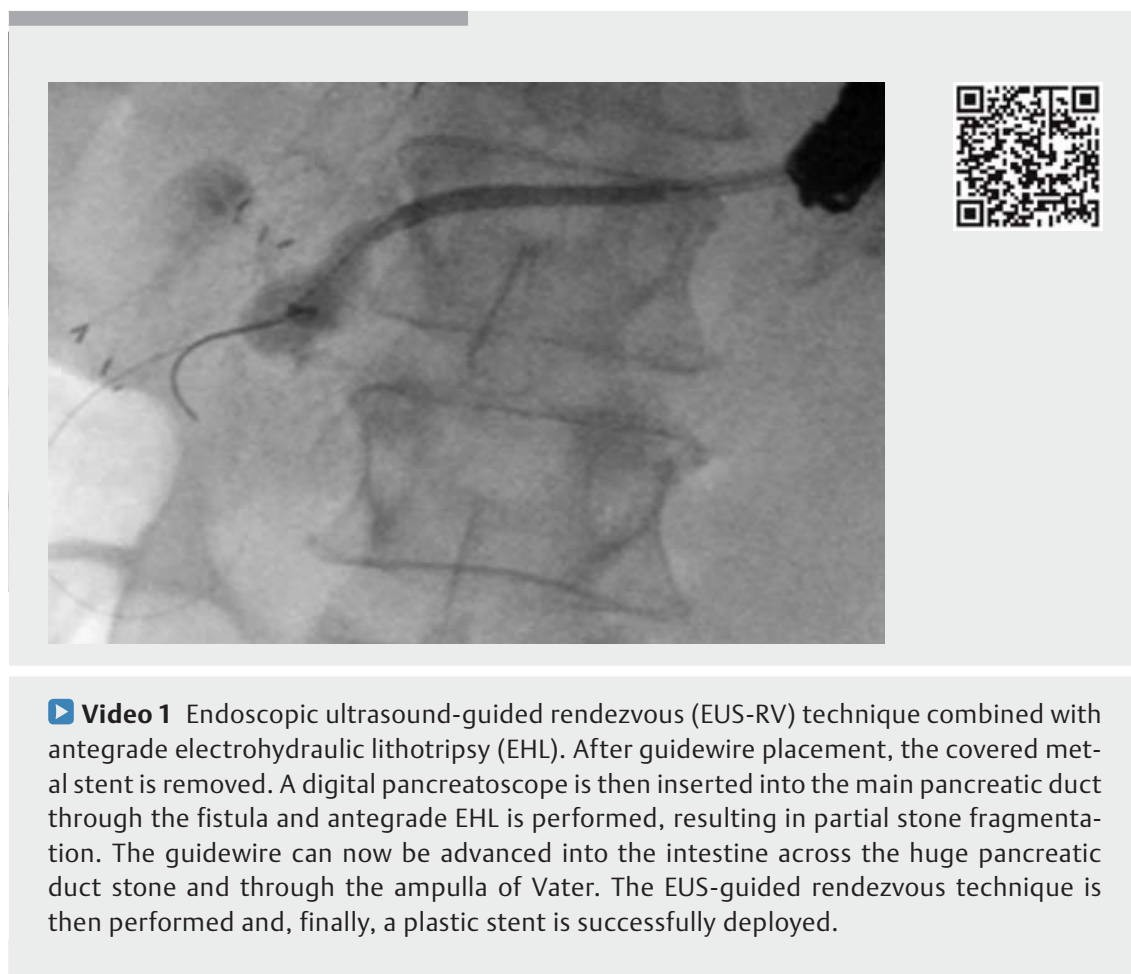

of the catheter across the huge pancreatic duct stone. Finally, a plastic stent was deployed without any adverse events ( Fig. 3 c; $\triangleright$ Video 1 ).

Our technique may be useful for situations where it is challenging to pass the guidewire across a site of obstruction.

Endoscopy_UCTN_Code_TTT_1AS_2AD

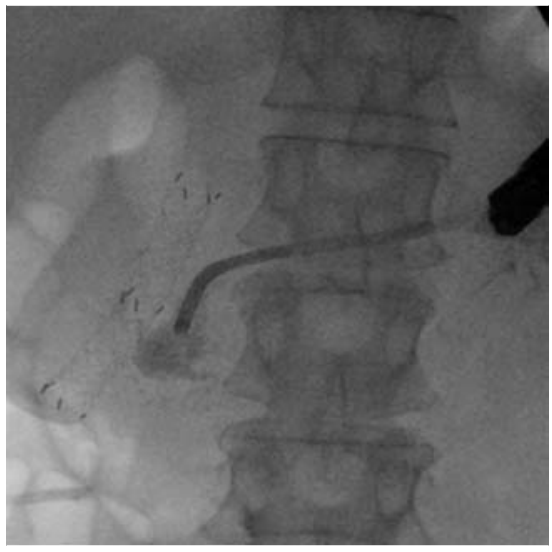

Fig. 1 Radiographic image showing antegrade electrohydraulic lithotripsy being performed through an endoscopic ultrasound-guided pancreatic duct drainage route.

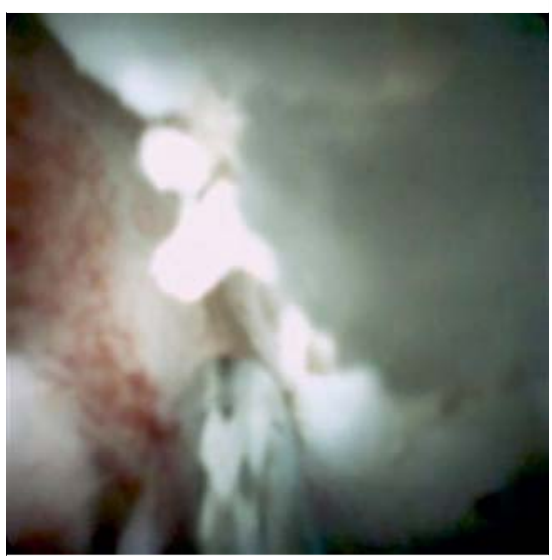

Fig. 2 Endoscopic view showing partial fragmentation of the pancreatic duct stone. 

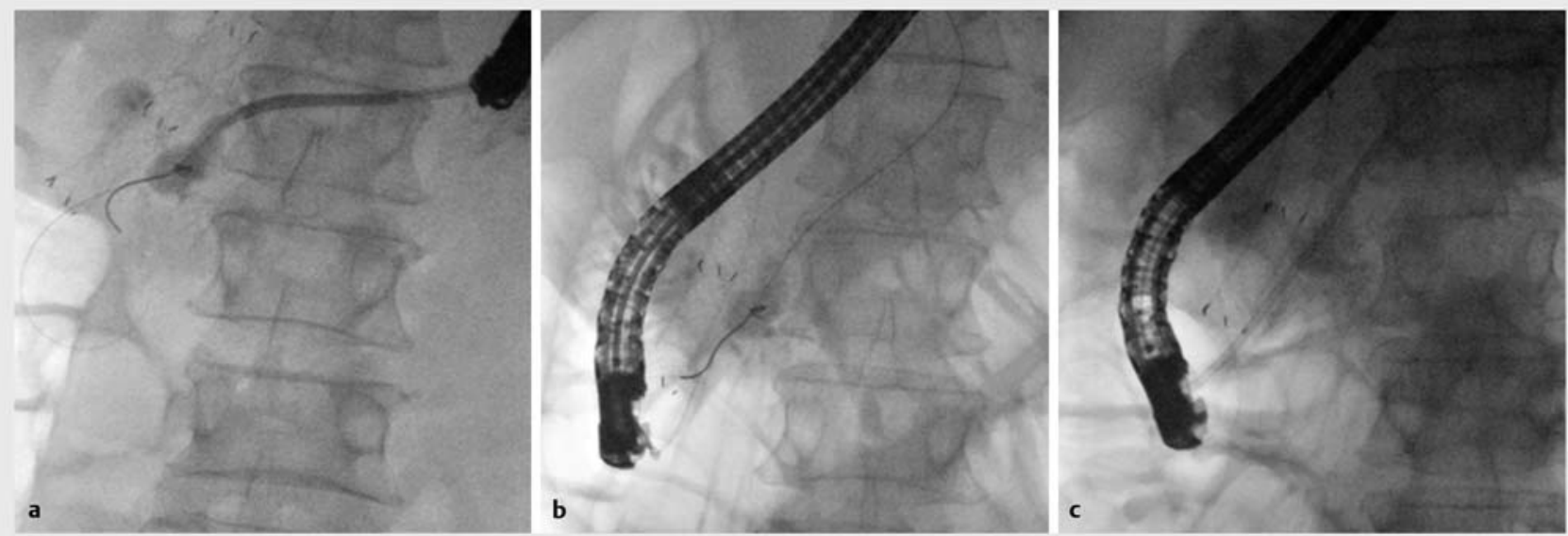

- Fig. 3 Radiographic images showing: a the guidewire being successfully advanced beyond the huge pancreatic duct stone and through the ampulla of Vater into the intestine; b endoscopic ultrasound-guided rendezvous technique being attempted; $\mathbf{c}$ a plastic stent successfully deployed.

\section{Competing interests}

None

The authors

\section{Takeshi Ogura, Nobu Nishioka, Masanori} Yamada, Kazuya Ueshima, Kazuhide Higuchi 2nd Department of Internal Medicine, Osaka Medical College, Osaka, Japan

\section{Corresponding author}

\section{Takeshi Ogura, MD}

2nd Department of Internal Medicine, Osaka Medical College, 2-7 Daigakuchou, Takatsukishi, Osaka 569-8686, Japan Fax: +81-72-6846532

oguratakeshi0411@yahoo.co.jp

\section{References}

[1] Isayama H, Nakai Y, Kawakubo K et al. The endoscopic ultrasonography-guided rendezvous technique for biliary cannulation: a technical review. J Hepatobiliary Pancreato Sci 2013; 20: $413-420$

[2] Tsuchiya T, Itoi T, Sofuni A et al. Endoscopic ultrasonography-guided rendezvous technique. Dig Endosc 2016; 28: $96-101$

[3] Shiomi H, Yamao K, Hoki N et al. Endoscopic ultrasound-guided rendezvous technique for failed biliary cannulation in benign and resectable malignant biliary disorders. Dig Dis Sci 2018; 63: $787-796$

[4] Iwashita T, Yasuda I, Mukai T et al. EUSguided rendezvous for difficult biliary cannulation using a standardized algorithm: a multicenter prospective pilot study (with videos). Gastrointest Endosc 2016; 83: $394-400$

\section{Bibliography}

DOI https://doi.org/10.1055/a-0866-9082

Published online: 25.3.2019

Endoscopy 2019; 51: E149-E150

(c) Georg Thieme Verlag KG

Stuttgart · New York

ISSN 0013-726X

\section{ENDOSCOPY E-VIDEOS}

https:/|eref.thieme.de/e-videos

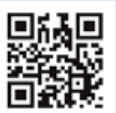

Endoscopy E-Videos is a free access online section, reporting on interesting cases and new techniques in gastroenterological endoscopy. All papers include a high quality video and all contributions are freely accessible online.

This section has its own submission website at

https://mc.manuscriptcentral.com/e-videos 